\title{
KUASA ALGORITMIK DALAM MASYARAKAT DIGITAL (INTERPRETASI PANDANGAN FOUCAULT ATAS TEKNOLOGI)
}

\author{
Wamil Nur', Suratman Kayano ${ }^{2}$ \\ ${ }^{1}$ Sekolah Tinggi Manajemen Informatika dan Komputer Handayani \\ ${ }^{2}$ Universitas Hasanuddin \\ E-mail: wamilnoer.wn@gmail.com
}

\begin{abstract}
Nowadays, study about digital society had been excessively done. This study could not be released by quickly developing innovation of technology in many flanks human life. Innovations of technology showed optimism and pessimism in various realm. The development of speed spaces expressed phenomenon moreover argumentation which sanctioning human ability to manage the technology that they were created. Therefore, this study tries to become disentangled technology development by using Michael Foucault's conceptual framework for explaining algorithmic power subjects and algorithmic governmentality in digital society. This study used qualitative descriptive approach with document research method along with content analysis method from primary resource and secondary resource till this study can be able to answer questions which was the basis why this study shall be doing. The results of this research shows there are power relations among actors like country and global capitalism within constructing freedom fantasies and democracy on digital society. For creating submissive society, every power actors used development of technology to predict and control critical awareness of society pass through algorithmic subjects and governmentality. As expressed by Michael Foucault, technology had been created for power to dominate digital society and created normality in human life. This study was offering practical steps to critical people to formulate algorithmic governmentality in a way to build their own technology to transform specific goals achievement like happiness, purity and wisdom as well as perfection and eternity.
\end{abstract}

Keywords: Algorithmic Governmentality; Technology; Power

\section{PENDAHULUAN}

$\mathrm{P}$ erkembangan inovasi teknologi digital memicu kecepatan-kecepatan di berbagai sisi dan menyebabkan terjadinya perubahan yang radikal. Perubahan radikal ini dikenal dengan istilah disrupsi. Disrupsi menciptakan inovasi yang akan menggantikan seluruh sistem lama dengan cara-cara baru. Menurut Renald Khasali, Disrupsi akan mengantarkan manusia dari masyarakat pertanian menjadi masyarakat industri dan jasa hingga menjadi masyarakat digital (Kasali, 2017). Lahirnya inovasiinovasi baru menjadi ancaman sekaligus peluang bagi manusia. Christian Fuchs 
mencatat bahwa pesatnya inovasi teknologi digital memicu optimisme dan juga kecemasan tersisa sebagian kecil kritisisme (Chandler \& Fuchs, 2007).

Dalam pengantar bukunya Cristian Fuchs mencatat bahwa kaum optimis teknologi-teknologi digital telah secara digital mentransformasikan dunia, menjanjikan bentuk-bentuk komunitas yang baru, cara-cara alternatif untuk mengetahui dan merasakan, inovasi kreatif, kultur partisipatif, aktivisme berjejaring dan persemaian demokrasi. Sementara itu kaum pesimis berargumen bahwa teknologi digital sama sekali tidak membawa perubahan positif, melainkan justru memperparah kedalaman dan perluasan dominasi melalui bentuk-bentuk kontrol yang baru seperti jejaring otoritarianisme, dehumanisasi digital, alienasi 2.0, jejaring eksploitasi dan bangkitanya surveillance society.

Sedangkan kaum kritisisme menolak tunduk pada berbagai bentuk narasi kebenaran tunggal dari sistem pengetahuan dan kuasa dan kerja-kerja pendisiplinan delusional di balik teknologi tersebut (Chandler \& Fuchs, 2007). Meskipun di dominasi oleh kaum optimis dan hidup bernaung dalam ekosistem digital, kaum kritis berani mengambil jarak dan mengkalkulasi atas berbagai kemungkinan, potensi, resiko, limitasi, dan ideologi di balik aktivitas digital yang dilakukan. Kaum kritisisme ini tidak mudah terklasifikasikan. Kaum kritisisme ini berada dimana-mana, cair dan berserak seperti yang diilustrasikan oleh Hardt sebagai multitude (Hardt, 2007).

Dalam masyarakat digital, kaum optimis mendominasi perubahan-perubahan yang terjadi. Dominasi kaum optimis berlangsung pada jenjang struktural maupun gugus sektoral, mulai pada tataran global, nasional dan lokal. Narasi-narasi gemilang tentang revolusi 4.0 atau artificial intelligence seolah difantasikan seperti yang diungkapkan oleh Yuval Noah Harari dalam buku Homo Deus "Deus ex Machina". Fantasi manusia tentang kemunculan Tuhan dari dalam mesin atau artificial intelegent (Harari, 2017). Kemunculan kecerdasan buatan adalah sebentuk neo-fetishism ala subyek-subyek algoritmatik dalam masyarakat untuk fantasi kebebasan, keadilan dan kesejahteraan manusia di era kapitalisme digital.

Eric Scmith dan Jared Cohen mencatat bahwa internet merupakan satu dari segelintir hal yang dibangun manusia. Penemuan internet menyebabkan ledakanledakan besar hingga membuat revolusi industri ke 4 yang menyempurnakan revolusi sebelumnya. Internet adalah jejaringnya jejaring, jejaring sistem komputer raksasa dan terpusat yang dirancang untuk menyebarkan informasi dengan protokol standar yang khusus (Scmith \& Cohen, 2014). Perkembangan pesat internet ditunjang dengan algoritma teknologi informasi. Algoritma mendorong kecepatan pembentukan, interaksi dan pertumbuhan ukuran jejaring, meningkat berkali-kali lipat. Pada era digital, konektivitas telah menjadi hal mendasar bagi semua orang.

Algoritma adalah urutan logis langkah-langkah penyelesaian masalah secara sistematis. Menurut Rinaldi Munir dalam bukunya Matematika Diskrit, Algoritma yang bagus adalah algoritma yang meminimunkan kebutuhan ruang dan waktu (Munir, 2010). Algoritma adalah instruksi matematis, sebagaimana yang diungkapkan oleh Ed Finn yang berjudul "What Algorithms Want: Imagination in the Age of Computing" algoritma adalah perangkat matematis untuk memanipulasi data atau mengkalkulasi pemecahan masalah. Algoritma komputasi ini ada di mana-mana (Finn, 2017). Pada dasarnya, digital civilization dibangun atas dasar algoritma komputasi. Masyarakat digital disuguhi algoritma komputasi di mana-mana mulai, dari pasar saham, komposisi musik, kemudi mobil, menulis artikel berita dan lain-lain. 
Logika algoritmik ini banyak digunakan juga untuk menemukan efesiensiefesiensi baru pada penginapan, transportasi, layanan-layanan personal lainnya oleh para perusahaan seperti Grab, Gojek, Tokopedia dan Reddoors. Algoritma menggunakan logika instrumental untuk mengkalkulasi keputusan-keputusan dan kebutuhan-kebutuhan manusia dalam mengotomasi dan memprediksi aktivitas seharihari.

Dalam masyarakat digital yang berbagai aktivitasnya dipelajari melalui algoritma komputasi menghadapi tantangan baru. Terlebih pada kaum kritis dalam membatasi dan mengkalkulasi segala bentuk narasi kebenaran tunggal dan kerja-kerja pendisiplinan delusional dalam ekosistem digital. Pendisiplinan delusional ini dapat dibaca menggunakan disiplinary dan governmentality-nya Foucault. Foucault memandang konsepsi tentang tubuh merupakan bagian sentral dalam beroperasinya relasi kekuasaan.

Disciplinary power merupakan gambaran dari kekuasaan yang beroperasi terhadap tubuh. Menurut Foucault, disciplinary power adalah teknologi kekuasaan yang dijalankan untuk mendisiplinkan tubuh dan membuatnya menjadi tubuh patuh dan berguna. Disciplinary power digunakan untuk menunjuk suatu bentuk kekuasaan dan wujud teknologi atau mekanisme beroperasinya kekuasaan (Foucault, 1982).

Disciplinary power beroperasi dengan cara-cara positif. Disiplinary power membentuk tubuh menjadi patuh dan berguna, dalam model disciplinary power berupa rezim kebenaran dan bekerja pada tubuh individu. Sementara itu, peluasan dari disciplinary power disebut governmentality. Subyek governmentality adalah populasi. Governmentality berada pada level negara sehingga operasinya dapat diakui. Pada dasarnya govermatility dijalankan oleh negara. Foucault berpendapat melalui governmentality. Kekuasaan diinternalisasi dalam tubuh sosial (Foucault, 1991).

Dalam analisis geneologi, tubuh dipandang sebagai objek pengetahuan dan target beroperasinya kekuasaan. Foucault meletakkan tubuh pada ranah politik, tertanam dalam relasi kekuasaan yang membuat tubuh menjadi patuh dan produktif serta berguna secara politik-ekonomi. Foucault memahami kekuasaan bekerja melampaui cara-cara hegemonik, dalam interpretasi Mona Lilja dan Stellan Vinthagen bahwa Foucault mengkonsepsikan dengan menyebutnya governmentality (Lilja \& Vinthagen, 2014). Oleh karena itu, penulis mengangkat tema ini untuk melihat bagaimana kuasa algoritma bekerja dan berusaha menguraikan pandangan Foucault terhadap perkembangan teknologi saat ini serta apa yang seharusnya dilakukan agar kaum kritis dapat tetap menemukan pendekatan-pendekatan baru dalam menghadapi kuasa algoritma yang ada di masyarakat digital.

\section{METODE PENELITIAN}

Penelitian ini menggunakan pendekatan kualitatif deskriptif dengan metode penelitian kepustakaan untuk mendeskripsikan proses kerja dan dampak kuasa algoritmatik dalam masyarakat digital. Sumber data diperoleh dari sumber-sumber umum yaitu teori-teori yang menguraikan tentang masyarakat digital serta teori-teori relasi dominasi dan relasi kuasa seperti yang diungkapkan oleh Michael Foucault. Sumber sekunder didapatkan melalui observasi melalui jurnal hasil penelitian dengan pembahasan dan pendekatan yang sama dengan penelitian ini. Pada dasarnya penelitian ini menggunakan persfektif Foucaultian yang memfokuskan pada uraian disciplinary 
power dan governmentality. Untuk dapat menjawab masalah-masalah yang menjadi dasar penulisan jurnal ini. Maka penulis melakukan content analysis dengan mengamati fenomena-fenomena sosial yang dikonstruksi menggunakan kuasa algoritmik dalam masyarakat digital.

\section{HASIL DAN PEMBAHASAN}

Dalam masyarakat digital saat ini di mana kesadaran dan tindakan subyek telah dibentuk dan ditentukan oleh kuasa-kuasa struktur hasil bentukan rumus-rumus algoritmik. Dalam proses pembentukan kesadaran, disciplinity power beroperasi untuk menguasai tubuh agar menjadi patuh dan berguna. Kekuasaan model ini dapat berlangsung efektif dalam institusi seperti pendidikan atau sekolah. Penguasaan ini berusaha menginternalisasikan penundukan dan menjadikannya seolah sebagai suatu keadaan yang normal. Sementara itu, disciplinity power beroperasi dalam skala yang lebih besar melalui negara seperti apa yang disebutkan Foucault sebagai governmentality.

Dalam masyarakat digital, disciplinity power dan governmentality bisa dijelaskan melalui bentuk relasi kuasa yang berlangsung antara kapital global, negara, pendidikan tinggi, civitas akademik hingga masyarakat luas sebagai pusaran kuasa (Allmer, 2019). Menginterprestasikan tulisan Allmer bahwa kontrol negara dan kapitalisme global telah berlangsung intensif dalam rentang beberapa dekade belakangan. Keberhasilan kapitalisme global bertekstur digital telah memproduksi subyek-subyek algoritmik.

Masyarakat digital menikmati berbagai aplikasi di smartphone seperti belanja, traveling, transportasi, finansial teknologi (fintech) mempertajam corak konsumerisme dalam masyarakat. Aplikasi-aplikasi Gojek, Traveloka, Tokopedia, Bukalapak, Ovo, Oyo dan Reddoorz terasa membantu dan mempermudah hidup penggunanya. Namun di balik narasi-narasi kemudahan hidup terdapat narasi-narasi yang menyembunyikan kegetiran dan kemirisan hidup di masyarakat digital.

Sebagai contoh, dalam birokrasi negara khususnya dalam pengukuran kinerja pegawai. Negara menciptakan sistem pengukuran kinerja berbasis digital dan pegawai akan berusaha patuh dan tunduk dalam arena-arena pegawasan negara dan pasar di mana subyek dianggap sebagai titik-titik terawasi dengan menggunakan algoritma sebagai sebuah panopticon kuasa ekonomi politik. Sehingga manusia tidak memiliki kehendak atas kesadaran mereka sendiri dalam melakukan aktivitas di luar dari apa yang ditentukan oleh algoritmik governmentality. Governmentality algoritmik memproduksi subyek-subyek algoritmik yang diperlakukan secara "radikal" sematamata sebagai data-data kecil yang di defenisi, manuver dan maknanya ditentukan oleh otomasi algoritmis berbasis sistem prediksi dan kontrol.

Subyek-subyek algoritmik berserakan dalam kapitalisme digital, kapitalisme telah menjadi wajah baru dalam proses pendefenisian relasi produksi, sosial, ekonomi, politik dan budaya masyarakat kita saat ini. Dalam relasi sosial yang demikian, kaum optimis menganggap bahwa individu akan semakin terbebaskan dan mampu menyusun inovasi-inovasi baru serta terlibat aktif dalam proses politik karena teknologi hanya berjarak sekian mili-senti dari ibu jari. Dalam politik, teknologi digital dianggap berkontribusi terhadap peningkatan kualitas demokrasi partisipatif, menumbuhkan kesadaran berkewarganegaraan, dan mentransformasi praktik mikro politik. 
Sementara itu, senada dengan studi politik tersebut di ranah ekonomi, Wendy Grossman menyanjung kehadiran internet dan inovasi kecerdasan buatan sebagai episode sejarah yang mengubah dunia menjadi arena yang lepas dari kemungkinankemungkinan tunggal dan membuka ruang independensi sehingga memiliki kapasitas untuk membuka lapangan kerja baru yang memangkas relasi-kuasa lama antara pemodal dan pekerja. Pandangan-pandangan optimis di atas terasa tunggal dan delusional (Drakopoulou et al., 2016). Sehingga penting untuk melakukan refleksi kritis atas pandangan yang terasa sangat hegemonik tersebut. Mengingat apa yang dikatakan oleh Foucault bahwa disciplinary power akan bekerja melalui governmentality sehingga terlihat legitime termasuk dalam konteks wacana. Conroy bahkan menyebutkan bahwa utopia akan meningkatnya kualitas pengetahuan di mana pengetahuan berserak setengah-setengah, tidak utuh, hingga melahirkan kepalsuan-kepalsuan politis seperti halnya hoax. Lanjut, Merylina Lim mencatat bahwa subyek-subyek malah tenggelam dalam palung-palung algoritmis sebagai dampak dari algoritma pasar yang terus menerus menyerang manusia digital dengan konten-konten berbasis pola tindakan konsumsi (Lim, 2017).

Menurut Heru Nugroho, secara umum terdapat tiga urgensi yang patut mendapatkan perhatian lebih antara lain: pertama, sistem prediksi dan kontrol algoritmik yang justru membentuk individu-individu hari ini sebagai subyek yang tidak otonom dan terkonsentrasi secara sukarela pada framing dominan big data dan trend yang diciptakan oleh industri digital raksasa (Nugroho, 2014). Urgensi pertama ini adalah penanda utama dari era hilangnya ruang-ruang privat. Kedua, ketimpangan akibat digitalisasi dan teknologisasi yaitu ketimpangan kepemilikan data dan ketimpangan persebaran jejaring digital. Ketimpangan kepemilikan data ini terjadi saat subyek-subyek digital menyediakan informasi dan pengetahuan secara sukarela kemudian secara diam-diam oleh server-server besar pada tingkat lanjut mengkonversi data tersebut menjadi keuntungan ekonomi. Sementara itu, ketimpangan persebaran jejaring digital terjadi sebagai dampak dari ketimpangan akses jaringan internet yang hanya ada di daerah perkotaan. Kondisi ini akan menyebabkan persebaran di luar sebaran umum dalam kumpulan data dianggap sebagai anomali dan olehnya bukan bagian dari normalitas. Ardau menyebut kondisi ini sebagai otherness.

Urgensi Ketiga adalah masa depan tenaga kerja dalam era digital. Kehadiran teknologi dianggap belum mampu mengurangi angka pengangguran, seperti revolusi sebelumnya, revolusi teknologi akan menghilangkan dan menghapus pekerjaan yang tidak relevan dengan dengan perkembangan zaman. Sementara itu, perubahan formasi tenaga kerja, sektor-sektor kreatif yang berurusan dengan ide, pengetahuan dan emosi akan diminati oleh pasar kerja, Lazzarto menyebut ini dengan istilah immaterial labour. Pemilik immaterial labour ini dekat dengan pemilik data. Terakhir penguasaan data dan sumber daya akan semakin terfokus pada segelintir konglomerat. Ketimpangan yang eksploitatif bagi para tenaga kerja di mana perusahaan-perusahaan platform diuntungkan dengan kuasa penuh untuk menetukan sistem "bagi hasil" dengan didukung oleh skema outsourching dan informalisasi tenaga kerja. Subyek-subyek digital semakin terpinggirkan, tidak memiliki kehendak dan patuh serta tunduk atas teknologi.

Melihat kerentanan subyek-subyek alogritmik dan kuatnya dominasi governmentality atas tubuh yang patuh dan tunduk. Penting bagi subyek untuk mengacu kembali pada pandangan Foucault atas dominasi teknologi dalam sistem kontrol modern. Dalam pandangan Foucault, ada empat tipe utama dari teknologi yaitu (1) 
Teknologi produksi, yang memungkinkan kita memproduksi, mentransformasikan atau memanipulasi segala sesuatu. (2) Teknologi sistem tanda, yang memungkinkan kita menggunakan tanda-tanda, makna-makna, simbol-simbol dan penandaan. (3) Teknologi-teknologi kekuasaan, yang menentukan perilaku individu dan memasukkannya pada tujuan atau dominasi tertentu, suatu proses objektivikasi subyek. (4) Teknologi-teknologi diri, yang memungkinkan individu-individu melakukan, dengan cara-caranya sendiri ataupun bantuan orang lain, sejumlah tindakan terhadap tubuh, jiwa, pikiran dan perilaku serta cara hidup mereka untuk bertransformasi mencapai tataran tertentu seperti kebahagiaan, kesucian dan kearifan serta kesempurnaan dan keabadian.

Kerangka konseptual dan analisa Foucault di atas membantu kita untuk menafsirkan sekaligus membongkar logika kerja subyek-subyek algoritmik dan governmentality yang tersembunyi di balik gelombang euforia jutaan penggunaan teknologi digital dalam fantasi kebebasan dan demokrasi yang menciptakan disiplinity power atas tubuh dan pikiran yang tunduk serta patuh dalam masyarakat digital.

\section{KESIMPULAN}

Dalam masyarakat digital, Governmentality algoritmik memproduksi subyeksubyek algoritmik yang diperlakukan sebagai data-data kecil yang di defenisi, manuver dan maknanya ditentukan oleh otomasi algoritmis berbasis sistem prediksi dan kontrol. Subyek-subyek algoritmik ini beroperasi membentuk defenisi dan makna sendiri agar kesadaran manusia dapat patuh pada relasi kuasa yang ada. Relasi kuasa yang terjadi antara negara dan kapitalisme global memudahkan penguasaan di berbagai sisi dalam masyarakat digital. Sementara itu, berbagai kerentanan subyek-subyek algoritmik yang ada saat ini menyebabkan masyarakat harus menemukan formulasi baru dalam menghadapi kemajuan teknologi agar tidak terjebak pada fantasi-fantasi yang ditawarkan oleh teknologi.

Dengan menggunakan kerangka konseptual Foucault, kita dapat menggunakan teknologi-teknologi diri agar subyek dapat hidup dan melakukan perlawanan atau resistensi atas dominasi teknologi-teknologi kuasa dominasi seperti governmentality algoritmik bisa disemai dan ditumbuhkan kembali melalui formasi subyek kritis dengan cara memperbesar injeksi spirit dan etos hidup maupun etos kerja secara kolektifkolegial bukan dividual (pisah-pisahan). Sehingga masyarakat digital mampu bertransformasi untuk mencapai tataran tertentu seperti kebahagiaan, kesucian dan kearifan serta kesempurnaan dan keabadian.

\section{DAFTAR PUSTAKA}

Allmer, T. (2019). Academic Labour, Digital Media and Capitalism. Critical Sociology. https://doi.org/10.1177/0896920517735669

Chandler, D., \& Fuchs, C. (2007). Digital Objects, Digital Subject. In Impressions.

Drakopoulou, S., Grossman, W., \& Moore, P. (2016). The campaign for digital citizenship. Soundings. https://doi.org/10.3898/136266216818497785

Finn, E. (2017). What algorithms want: Imagination in the age of computing. In What Algorithms Want: Imagination in the Age of Computing. https://doi.org/10.5585/dialogia.n27.7781 
Foucault, M. (1982). The Subject and Power. Critical Inquiry. https://doi.org/10.1086/448181

Foucault, M. (1991). Governmentality. In The Foucault Effect.

Harari, Y. N. (2017). Homo Deus. In Homo Deus. https://doi.org/10.17104/9783406704024

Hardt, M. (2007). Empire and Multitude. Monthly Review. https://doi.org/10.3167/sa.2007.510204

Kasali, R. (2017). Millennials dan Disruption. Rumah Perubahan.

Khasali, R. (2018). Disruption, Menghadapi Lawan-lawan tak terlihat dalam peradaban uber, Jakarta: PT. Gramedia Pustaka.

Lilja, M., \& Vinthagen, S. (2014). Sovereign power, disciplinary power and biopower: resisting what power with what resistance? Journal of Political Power. https://doi.org/10.1080/2158379X.2014.889403

Lim, M. (2017). Freedom to hate: social media, algorithmic enclaves, and the rise of tribal nationalism in Indonesia. Critical Asian Studies. https://doi.org/10.1080/14672715.2017.1341188

Mudhoffir, A (2013). Teori Kekuasaan Michael Foucault: Tantangan bagi Sosiologi Politik, Jurnal Sosiologi Masyarakat Vol. 18, No. 1 Januari 2013.

Munir, R. (2010). Matematika Diskrit, Bandung: Informatika Bandung.

Nugroho, Heru dkk. (2019). Membongkar Delusi Subyek-Subyek Algoritmik Dalam Masyarakat Digital: Prospek Emansipasi, Keadilan dan Inklusi Sosial dalam Ruang Kecepatan, Makalah, Fakultas Ilmu Sosial dan Ilmu Politik UGM

Schiller, D. (1999) Digital Capitalism: Networking the Global Market Society, Massachusetts: The MIT Press.

Scmith, E., \& Cohen, J. (2014). The New Digital Age, Cakrawala Baru Negara, Bisnis dan Hidup Kita, Jakarta: PT. Gramedia Pustaka.

Smart, B. (2004). Michael Foucoult, New York: Routledge. 